\title{
Възможности на отоакустичните емисии като скринингово изследване в неонаталния период
}

\author{
Ст. Марков, Ил. Йовчев \\ Катедра по УНГ-болести, Медицински университет - Пловдив
}

\section{Въведение}

Глухотата при деца - нейната ранна диагностика и лечение, е и си остава световен проблем (Harrison M, Roush J) ${ }^{1}$, за чието разрешаване съвременната медицина полага огромни и все по-успешни усилия, като добрите резултати се дължат на постижения не само в областта на медицината, но и на физиката и електрониката, и зависят от ранната и точна диагностика, позволяваща точен терапевтичен подход във всеки един отделен случай ${ }^{3}$.

OАЕ представляват кохлеарен феномен, който отразява функционалното състояние на външните слухови клетки, като те са описани за първи път от Кемп през 1978 година. Следващи проучвания доказват, че ОАЕ ce регистрират при нормално чуващи уши (Probst, 1990 г.) и се променят в различна степен при пациенти със слухови увреди.

Данни от СЗО показват, че откриването на вродената) глухота обикновенно става между 24 и 30 месец, освен ако не се извърши скринингово изследване на децата след раждането им. Това забавяне във времето се отразява върху правилното развитие на нервната им система.

Проведените до този момент проучвания и неонаталните слухови скрининги показват, че честотата на вродената слухова загуба се движи между 0.9 и 4 на 1000 новородени ("Универсален неонатален слухов скрининг чрез електрическа реакционна аудиометрия", П. Руев) $)^{2}$. 
Няколко са основните методики за извършване на неонатален слухов скрининг - (BERA, ABR, TEOAE, DPOAE) $)^{4,5,6}$, като всеки един от тях има различни предимства и недостатыци в сравнение с останалите. От 2001 година се забелязва тенденция за все по-широко използване при тези изследвания на апаратура, базирана на автоматизирани $\mathrm{OAE}^{7}$, ${ }^{8}$, които имат предимството да са по-евтини и попрости.

\section{Материал и методи}

Нашето изследване обхваща 200 новородени деца, които бяха изследвани в първите дни след раждането им, като за децата, родени без усложнения, и такива без престой в реанимация изследването се извърши на втория-третия ден от раждането, а при останалите в деня преди изписването им от родилното отделение - АГ-клиника, Медицински университет - Пловдив. Използван бе апарат за отчитане на TOAE на фирмата MAICO ERO-SCAN (Картина 1), който генерира серия от кликове, насочва ги към външния слухов проход и анализира спектьра на завръщащия се сигнал, като разделя шум от сигнал и определя тяхното съотношение. Като използва последователно свързани филтри, апаратът дава приблизителна оценка на функцията на външните ресничести клетки в широк честотен диапазон. MAICO ERO-SCAN може да отчита OAE в диапазон $500 \mathrm{~Hz}-4000 \mathrm{~Hz}$. В края на изследването апаратурата сама отчита "PASS" за преминалите теста (Картина 3) и "REFER" (Картина 4) за показалите отклонения от нормата, като запаметява до 50 резултата и при необходимост ги принтира.

При изследването на новородените бе използвана външна гъвкава сонда за апаратурата (Картина 2), като това в голяма степен улесни изследването и намали времето, необходимо за извършването му. Апаратурата за отчитане на TOAE на MAICO ERO·SCAN може да се настрои с различни параметри, като за нашето изследване бяха използвани следните настройки:

- брой на изследваните честоти - 6

- сила на кликовете - $65 \mathrm{~dB}$

- съотношение шум/сигнал - $4 \mathrm{~dB}$

- средно време на изследването - $64 \mathrm{sec}$

- брой на честотите с положителен резултат, необходими, за да се отчете "PASS" - 3

Изследването е бързо, неинвазивно и отчитането на резултата от него е базирано на принципа "всичко или нищо". В нашето проучване обхванахме 200 новородени деца (пьрвите дни след раждането), от тях 96 момчета и 104 момичета.

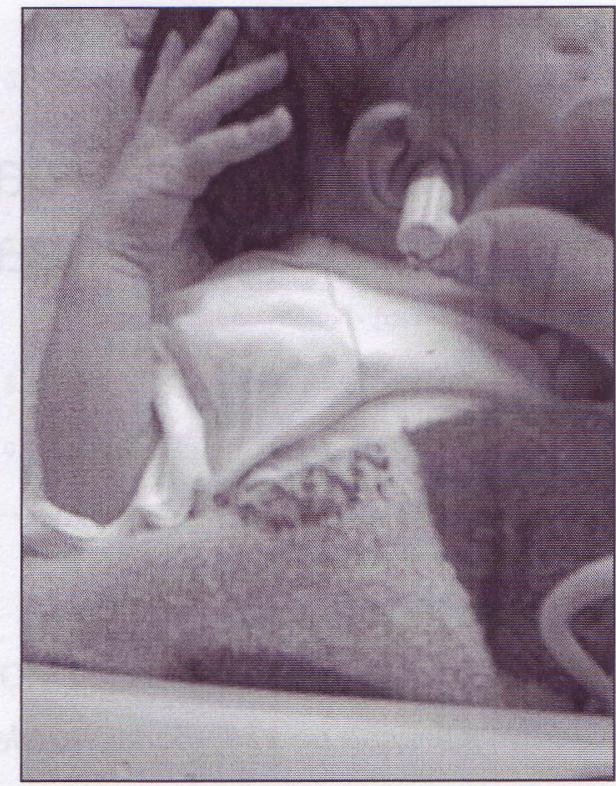

Снимка 1

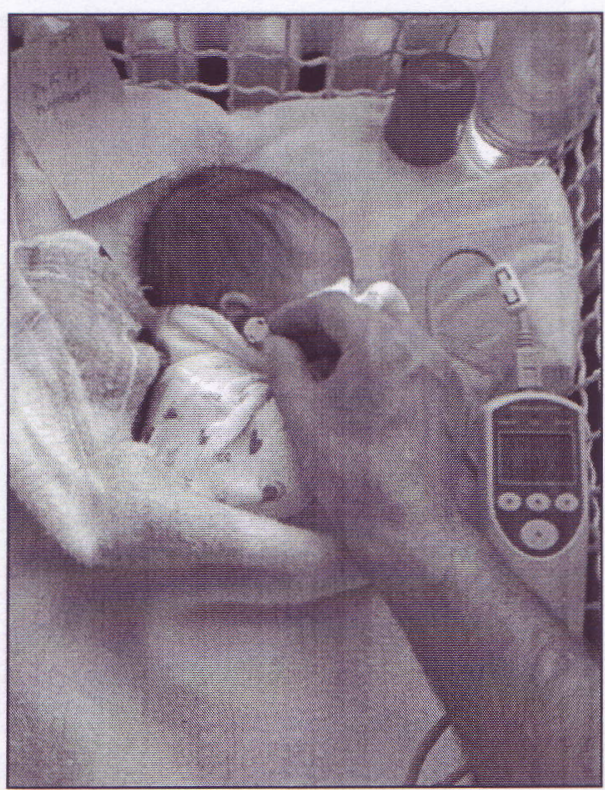

Снимка 2

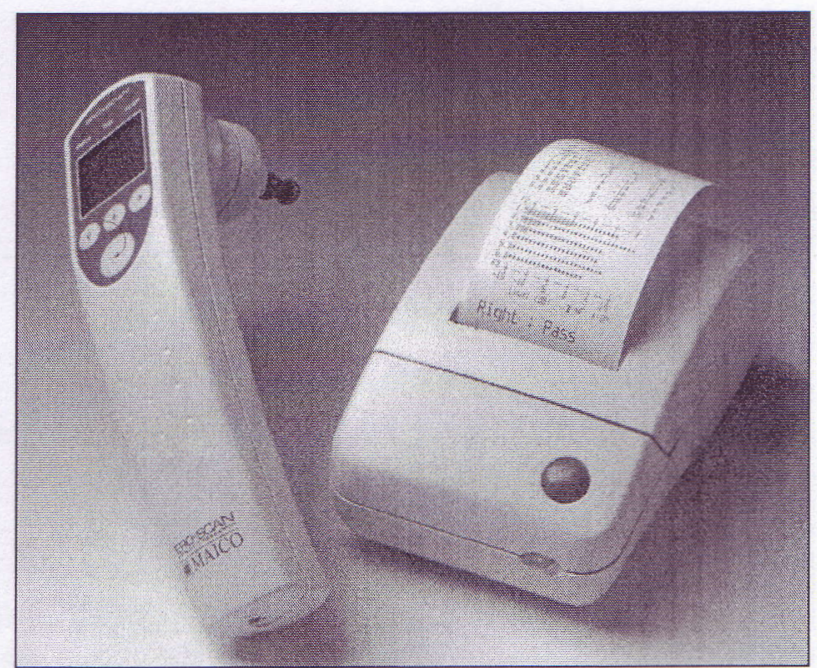

Картина 1 
На Таблица 1 се вижда разпределението им в групи според различни показатели - преминали и не преминали първоначалното изследване, двустранно или едностранно, не преминали пьрвото изследване и др. Общо 25 новородени показаха отклонения при първото изследване и бяха повикани след 1 месец за повторно тестуване, като се явиха 19 и всички те преминаха успешно второто тестуване (100\% PASS).

С повишено внимание изследвахме децата с рискови фактори по отношение на евентуална слухова увреда, като в нашето изследване те са разпределени така:

- с 1 рисков фактор: 28 деца

- с 2 рискови фактора: 3 деца

- с три рискови фактора: 1 дете

Повишено внимание бе отделено също така и на 16 от новородените, които след раждането си престояха повече от 5 дни в реанимацията по една или друга причина.

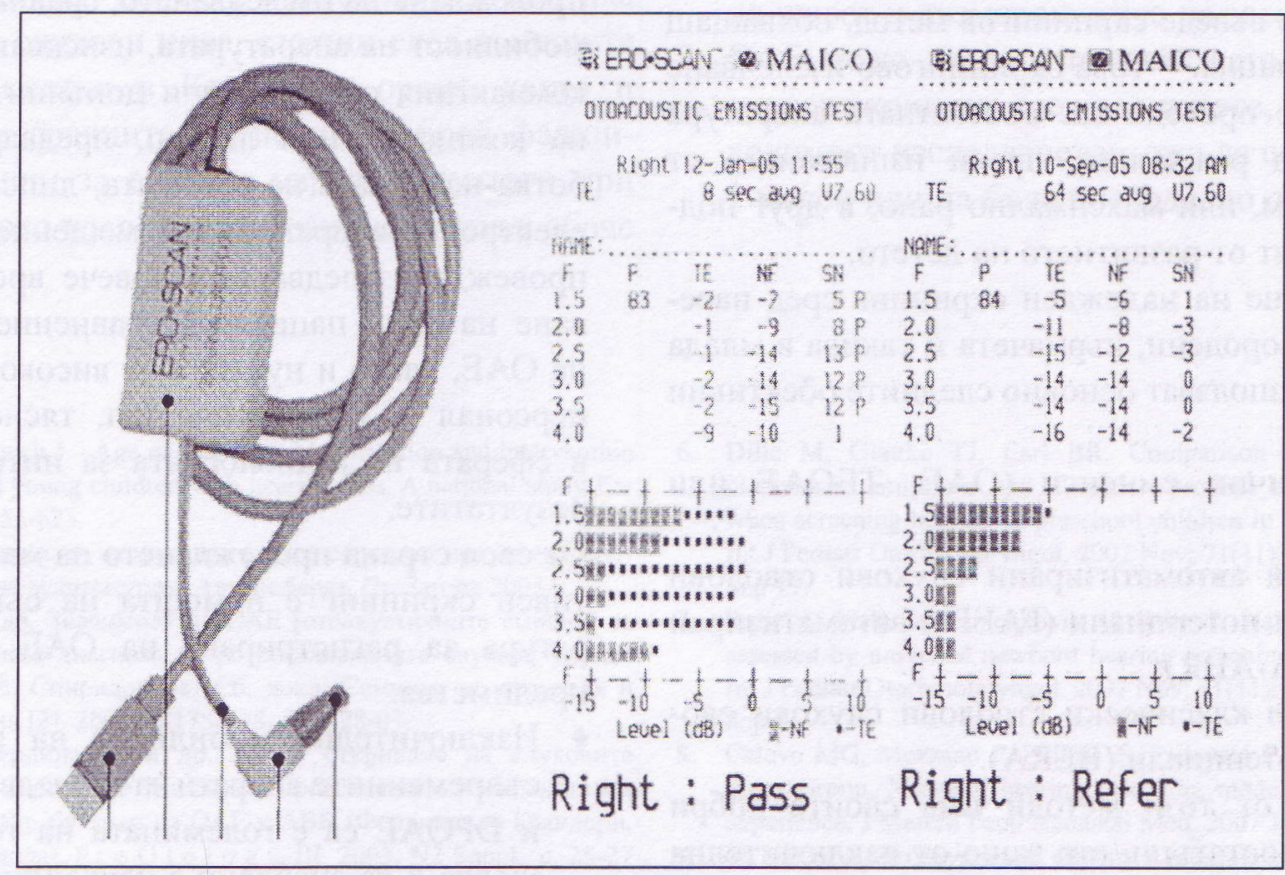

Картина 2

От изследваните новородени 115 са родени чрез нормално родоразрешение, 79 със секцио и 6 с помощта на форцепс.

\section{Таблица 1}

\begin{tabular}{|l|c|c|}
\hline & Момчета & Момичета \\
\hline Брой & 96 & 104 \\
\hline Среден ръст & 49.08 & 48.51 \\
\hline Средно тегло & 3315.8 & 3286.25 \\
\hline Преминали първия тест & 91 & 94 \\
\hline $\begin{array}{l}\text { Не преминали първия тест } \\
\text { за двете уши }\end{array}$ & 3 & 4 \\
\hline $\begin{array}{l}\text { Не преминали първия тест } \\
\text { за едното ухо }\end{array}$ & 12 & 6 \\
\hline
\end{tabular}

\section{Картина $3 \quad$ Картина 4}

\section{Резултати}

В това проучване сме обхванали 200 новородени за период от 8 месеца.

На първия етап от изследването с ТЕОАЕ 175 деца преминаха успешно теста и 25 (43\%) показаха отклонения, от които едностранно 18 (30,75\%) и двустранно 7 (12,25\%).

При второто изследване с ТЕОАЕ, извършено след 1 месец на показалите отклонение деца, всичките явили се 19 деца преминаха успешно тестуването $(100 \%)$.

Средното време, отделено за изследване на едно дете, е 10 минути. 


\section{Дискусия}

Ранната и точна диагностика на глухотата е ключов момент от цялостния лечебен процес на детската глухота. Въпреки множеството нови и изключително прецизни диагностични процедури обаче, все още в над $20 \%$ от случаите етиологичният причинител на слуховата увреда остава неоткрит, а се лекуват последиците - глухотата.

Адекватно развиващият се детски слух е предпоставка за развитието на говора при децата, а всяка слухова увреда, неустановена в максимално ранна възраст, е заплаха за развитието на речта и социалната интеграция на индивида, ето защо е необходимо да се въведе скринингов метод, обхващащ цялата популация., ${ }^{2,3}$ Това скринингово изследване трябва да се проведе със съответната апаратура веднага след раждането, преди изписването от родилния дом, или максимално рано, в друг подходящ момент от развитието на детето.

За провеждане на надежден скрининг сред населението (новородени, кърмачета и такива в млада възраст) се използват основно следните обективни методи:

- Отоакустични емисиси (OAE; TEOAE или DPOAE);

- Обективни автоматизирани слухови стволови евокирани потенциали (FAEР в автоматизиран вариант; А-ABR);

- Обективни класически стволови слухови евокирани потенциали (BERA).

Всеки един от тези методи има своите добри страни и недостатьци, ето защо от изключителна важност е подборът на съответната методика съобразно целта на съответното проучване, но въпреки това всеки един скринингов метод трябва да отговаря на следните основни характеристики:

- Масовост на скрининга (обхващане на популацията над 95\%);

- Ниска себестойност на изследването;

- Наличие на съответната апаратура и обучен персонал;

- Възможно най-ниска степен на фалшиво-положителни отговори при пьрвоначалния скрининг;

- Осигурена възможност за проследяване на пациентите, показали патологични отклонения;

- Максимална краткотрайност на изследването;

- Пълна точна, лесна за попълване и интерпретация документация.

Погледнато в световен аспект, два са методите за масов скрининг:
- Обективни автоматизирани слухови стволови евокирани потенциали

- Отоакустични емисии (OAE: TEOAE или DPOAE)

Провежданите досега в България скринингови програми (П. Руев) използват методите на автоматизираните слухови стволови потенциали. Тази методика има редица отлични характеристики, дължащи се на близостта ù c класическите слухови стволови евокирани потенциали, които са признати за "златен стандарт" в областта на аудиологията. Недостатъците на метода са свързани с необходимостта от звукоизолирано помещение за провеждане на изследването, сравнително слабата мобилност на апаратурата, изискваща дори в найкомпактния си вариант и допълнително наличие на компютър или лаптоп, предварителна обработка на кожата на пациента, липса на работеща електронна апаратура в помещението, в което се провежда изследването, повече време за изследване на един пациент в сравнение с изследване на OAE, както и нуждата от висококвалифициран персонал - УНГ-специалист, тясно профилиран в сферата на аудиологията за интерпретация на резултатите.

От своя страна провеждането на масов или селективен скрининг с помощта на съвременна апаратура за регистриране на ОАЕ има следните предимства:

- Изключителна мобилност на апаратурата съвременните апарати за изследване на ТЕОАЕ и DPOAE са с големината на телефонна слушалка и са снабдени с накрайници, позволяващи лесното провеждане на изследването независимо от възрастта на пациента.

- По-слабата чувствителност към околни дразнения по време на изследването - достатъчно е в стаята, където се провежда изследването, да е сравнително тихо, за да се получи желаният резултат. Това се дължи и на факта, че самият накрайник на сондата на апарата за ОАЕ уплътнява отвора на външния слухов проход, като по този начин предотвратява попадането на външен шум в ухото по време на тестуването. Единственото допълнително условие е липсата на церумен или при новородените Vernix caseosa, за да се осъществи тестуването.

- Изключително лесно интерпретиращи се резултати от тестуванията-съвременните апарати за изследване на ОАЕ работят на принципа "всичко или нищо", като в края на теста се получава както ясен отговор: Преминал-PASS съответно Hепреминал-REFER, така и графика на тесту- 
ването, позволяваща по-детайлна интерпретация на резултатите.

- Ниска себестойност на изследването - веднъж закупена, апаратурата при правилно съхранение може да се ползва дълго, като единствените необходими консумативи са батериите, с които се захранва, и принтерната лента, ако провеждащият изследването прецени, че е необходимо отпечатване на получените резултати.

- Краткотрайност на изследването 10-15 минути средно време на пациент.

Недостатыците на скрининговите програми, използващи методиката на отчитане на OAE, се заключават в това, че чрез тях не е възможна диагностика на увреди на слухови нива, стоящи след външните рецепторни клетки в Кортиевия орган, както и наличието на сравнително по-голям брой фалшиво положителни за слухова увреда резултати при първоначалното изследване. Този недостатък обаче

\section{Литература:}

1. Harrison M Roush J - Age of suspicion identification and intervention for infants and young children with hearing loss. A national study Ear Hear 1996 17-55-62

2. П. Руев. Универсален нсонатален слухов скрининг чрез електрическа реакционна аудиометрия. Автореферат, Ст. Загора 2003 г.

3. Д. Попова и др. Значимост на ОАЕ [отоакустичните емисии] за диференциалната диагноза на ретрокохлеарните слухови увреди (Д. Попова, Й. Спиридонова) Сб. докл. Семинар по отология и невро-отология [2], 2000, с. 175-178; 616. 28-07.

4. Грандори, Фердинандо и др. Ранно откриване на слуховите увреждания - опитът на Милано в провеждането на неонатален слухов скрининг, базиран на OAE и ABR (Фердинандо Грандори, Габриела Тогнола). P r o O $t$ o 1 o g у, III, 2003, N2 Suppl., с. 25-27 616.28-053.3(45)

5. Calevo M, Mezzano P, Zullino E, Padovani P, Serra G; and the STERN Group. Ligurian experience on neonatal hearing screening: clinical and epidemiological aspects. Acta Paediatr. 2007 Nov; 96(11): 1592-9. лесно се преодолява чрез повторно изследване, което също е кратковременно, илии при необходимост от по-голяма прецизност чрез включване на втори или трети етап в изследването на апаратура за диагностика на ССЕП.

\section{Изводи}

1. Диагностицирането на слуховите увреди при деца се извършва късно, особено на тези с малка слухова загуба.

2. Откриването на децата сьс слухова загуба в първите дни след раждането им с помощта на скрининг има потенциала да повлияе качеството на живот и възможностите на засегнатите.

3. OAЕ може да се използват като първоначален слухов скрининг след раждането, като при необходимост изследването може да се повтори след 1 месец или да бъде последвано от ABR.

6. Dille M, Glattke TJ, Earl BR. Comparison of transient evoked otoacoustic emissions and distortion product otoacoustic emissions when screening hearing in preschool children in a community setting. Int J Pediatr Otorhinolaryngol. 2007 Nov; 71(11): 1789-95. Epub 2007 Sep 17.

7. Prpic I, Mahulja-Stamenkovic V, Bilic I, Haller H. Hearing loss assessed by universal newborn hearing screening-The new approach. Int J Pediatr Otorhinolaryngol. 2007 Nov; 71(11): 1757-61. Epub 2007; Sep 6.

8. Calevo MG, Mezzano P, Zullino E, Padovani P, Scopesi F, Serra G; Stern Group. Neonatal hearing screening model: an Italian regional experience. J Matern Fetal Neonatal Med. 2007 Jun; 20(6): 441-8.

9. М. Милков. Отоакустични емисии - есенциален поглед. Списание "Международен бюлетин по оториноларингология" бр. 362007 г., c. 25-29. 